\title{
Factors related to work ability and well- being among women on sick leave due to long-term pain in the neck/shoulders and/or back: a cross-sectional study
}

\author{
Mamunur Rashid $^{1 *}$ (D, Marja-Leena Kristofferzon ${ }^{2,3}$, Marina Heiden ${ }^{1}$ and Annika Nilsson ${ }^{2,3}$
}

\begin{abstract}
Background: Musculoskeletal pain is one of the leading causes of sick leave, especially among women, in Western countries. The aim of the present study was to identify factors associated with work ability and well-being, respectively, among women on sick leave due to long-term pain in the neck/shoulders and/or back.

Methods: A cross-sectional study with a correlational design was conducted on women who were sick-listed due to long-term pain in the neck/shoulders and/or back. A total of 208 participants responded to a survey comprising eight instruments: Multidimensional Pain Inventory scale, General Self-Efficacy scale, Sense of Coherence scale, Coping Strategies Questionnaire, Demand-Control-Support Questionnaire, Hospital Anxiety and Depression Scale, Work Ability Index and Life Satisfaction questionnaire. Multiple linear regression analyses were performed to identify factors associated with work ability and well-being, respectively.

Results: Women who more strongly believed they would return to the same work had greater work ability ( $\beta=0.39$, $p<0.001)$, whereas women with higher pain intensity $(\beta=-0.30, p<0.001)$ and higher job strain $(\beta=-0.12, p<0.05)$ had lower work ability. Women with higher self-efficacy rated greater well-being $(\beta=0.14, p<0.05)$. As the women's scores for depression increased, their well-being decreased by $48 \%$, which was statistically significant $(p<0.001)$. The regression models for work ability and well-being were significant $(p<0.001)$, and their adjusted R- square values were $48 \%$ and $59 \%$, respectively.

Conclusions: The study suggests that the factors beliefs to be back at the same work, pain intensity and job strain are predictive of work ability. Moreover, the factors self-efficacy and depression seem to be predictive of well-being. The findings highlight factors that should be considered by health care professionals and policy-makers to guide attempts to reduce sick leave.
\end{abstract}

Keywords: Musculoskeletal pain, Sickness absence, Prognostic factors, Ability to work, Quality of life, Women

\section{Background}

Sick leave due to long-term Musculoskeletal Pain (MSP) is considered an increasing public health problem in Western countries $[1,2]$. The social economic costs of sick leave are immense owing to workers' compensation, medical expenses and productivity loss [3, 4]. Long-term pain in the neck, shoulders and back is one of the

\footnotetext{
* Correspondence: mamunur.rashid@hig.se

${ }^{1}$ Centre for Musculoskeletal Research, Department of Occupational and

Public Health Sciences, Faculty of Health and Occupational Studies,

University of Gävle, SE-80176 Gävle, Sweden

Full list of author information is available at the end of the article
}

leading causes of reduced work ability and well-being among workers [5]. Previous findings suggest that women have a higher prevalence of neck/shoulders and low back pain and are more likely to be on sick leave than men $[2,6,7]$.

The concept of work ability comprises the physical, psychological and social capability of a worker, which interact with the workers' health condition, physical and mental resources and work demands [8, 9]. In this study, work ability reflects the individual's perceived current and near future ability to perform work with respect to

(c) The Author(s). 2018 Open Access This article is distributed under the terms of the Creative Commons Attribution 4.0 International License (http://creativecommons.org/licenses/by/4.0/), which permits unrestricted use, distribution, and reproduction in any medium, provided you give appropriate credit to the original author(s) and the source, provide a link to the Creative Commons license, and indicate if changes were made. The Creative Commons Public Domain Dedication waiver (http://creativecommons.org/publicdomain/zero/1.0/) applies to the data made available in this article, unless otherwise stated. 
work demands, health and mental resources [10]. In general, well-being reflects the meaningfulness of life with regard to physical, mental and social dimensions [11], and in this study, well-being is assessed through 10 dimensions of life satisfaction with regard to daily living using a self-report checklist (LiSat- 11) [12]. Owing to the importance of work ability and well-being in the working population $[2,13-16]$, it is essential to understand which factors are important for work ability and well-being in this population. Previous systematic reviews have attempted to identify work-related and individual factors of importance for work ability and well-being, but they have done so in the general working population or among people with MSP. For example, van den Berg et al. [17] found that older age, obesity, poor musculoskeletal capacity, high mental work demands, poor physical work environment, high physical work load, lack of autonomy and lack of physical activity have a negative effect on work ability among people with long-term MSP. Another review by Hoogendoorn et al. [18] presented strong evidence indicating that low social support at work and low job satisfaction are related to reduced well-being among back pain patients. It is possible that the factors of importance for work ability and well-being among people who are sick-listed are different owing to the severity of their conditions $[5,8,19,20]$.

A recent systematic review showed that recovery beliefs, health and work capacity were important for return to work among people on sick leave due to long-term pain in the neck or back [16]. The authors concluded, however, that more studies were needed to confirm the results. Generating more knowledge about what is needed to improve work ability and well-being, and consequently to facilitate return to work in this population would benefit individuals as well as society. However, previous studies have primarily focused on both women and men with sub-acute or chronic pain who were working or on part-time sick leave [19-24]. As studies have shown that work tasks tend to differ between men and women, even in the same line of work [25, 26], it is possible that factors influencing work ability also differs between genders. Therefore, they should be investigated separately. Thus, the aim of the present study was to identify factors associated with work ability and well-being, respectively, among women on sick leave due to long-term pain in the neck/shoulders and/or back.

\section{Methods}

\section{Study design}

The study was cross-sectional and used a correlational design.

\section{Sample}

In spring 2016, a total of 600 women from central and northern Sweden were invited by the Swedish Social
Insurance Agency (SIA) to take part in the study. They were selected on the basis of their medical certificate, issued by their primary health care or hospital physician. Women were included in the study if they met the following criteria: 18 to 65 years of age; $\geq 50 \%$ sick leave from service (i.e., they could do part-time work); duration of sick leave $\geq 1$ month due to pain in the neck/shoulders (ICD code: M53.1, M54.2, M54.9, M75.8, M75.9 and M79.1) and/or back (ICD code: M54.4, M54.5, M54.9 and M79.1) for $\geq 3$ months. They should also be able to read, write and understand Swedish. The exclusion criteria were: rheumatoid arthritis, multiple sclerosis, stroke, cancer, Parkinson, bipolar disease, schizophrenia and pregnancy. An information letter and questionnaires were sent to the women; two reminders were sent out. Of the 600 women, 275 responded to the questionnaires, giving a response rate of $46 \%$. Of them, 67 were excluded based on exclusion criteria, thus 208 were included in the analyses. Because the Swedish Social Insurance Agency invited the women to take part in the study, the authors had no access to non-respondents' data. For this reason, the non-response analysis cannot be performed.

\section{Data collection}

Self-administered questionnaires based on eight instruments and a set of demographic variables such as age, education, country of birth, cohabitation, working conditions, economic situation, physical activity and beliefs to be back at the same work were sent to the women. In addition, a pain figure was included to collect information on the location of pain on the body [27]. Subscales from six instruments were treated as independent variables and two were used as outcome variables. A description of each instrument is provided below.

\section{Independent variables Pain intensity}

To assess pain intensity, the Multidimensional Pain Inventory (MPI- S) [28] was used. The psychosocial section (part 1) consists of 28 items forming five sub-scales. In the present study, we analyzed only one sub-scale: pain intensity, which consists of 3 items, where responses are made on a 7 -point Likert rating scale $(0=$ no pain; $6=$ extreme pain), and where higher scores indicate higher pain intensity. The internal consistency of the scale, measured using Cronbach's $\alpha$, was 0.76 .

\section{Self-efficacy}

To assess self-efficacy, the General Self-Efficacy (GSE) [29] scale was used. It consists of 10 items that respondents rated on a 4 -point Likert scale $(1=$ not true; $4=$ completely true). Total scores ranged from 10 to 40 points, higher values indicating greater general self-efficacy. The internal 
consistency of the scale, measured using Cronbach's $\alpha$, was 0.92 .

\section{Sense of coherence}

Sense of coherence (SOC) is part of the salutogenic approach of health that focuses on one's ability to identify resources for health and well-being. SOC is the capability to manage whatever the situation demands in life to perceive life as comprehensible, manageable and meaningful [30]. The SOC scale [30, 31], short version, was used to assess sense of coherence. The scale consists of 13 items, with total scores ranging from 7 to 91 points. The respondents rated items on a 7 -point scale $(1=$ never; $7=$ very often $)$, where higher scores represent greater SOC. The internal consistency of the scale, measured using Cronbach's $\alpha$, was 0.84 .

\section{Coping strategies}

Coping strategies were assessed using the Swedish version of the Coping Strategies Questionnaire (CSQ) [32], which consists of 50 individual items forming 8 sub-scales. In the present study, we used only three of the subscales: divert attention, ignore sensation, and increase behavioral activities. Each item was rated on a 7-point Likert scale ranging from $0=$ never to $6=$ always, higher values representing more frequent use of the coping strategy. The internal consistency values for the sub-scales, measured using Cronbach's $\alpha$, were $0.87,0.86$ and 0.86 , respectively.

\section{Job strain and support at work}

Job strain was assessed using the Demand Control Support Questionnaire (DCSQ) [33] which consists of 17 items forming four subscales: psychosocial demands, skills discretion, decision authority and support at work. For each item, responses were made on a 4-point Likert scale ranging from 1 (strongly agree) to 4 (strongly disagree). First, we constructed an index for each of the three scales: psychological demands, skills discretion and decision authority. Skills discretion and decision authority were then merged into one scale called decision latitude [34]. Afterwards, a job strain score was created by calculating the ratio between psychological demands and decision latitude, where higher values represent higher job strain [33]. For the subscale support at work, the values for the six items were summed to a total score, where higher values represent greater perception of support at work. The internal consistency of the scale, measured using Cronbach's $\alpha$, was 0.57 for job strain and 0.51 for support at work.

\section{Anxiety and depression}

Anxiety and depression were assessed using the Hospital Anxiety and Depression Scale (HADS) [35, 36] which consists of 14 items forming two scales: anxiety (7 items) and depression (7 items). Respondents rated each item on a 4-point Likert scale, where higher values indicate greater anxiety or depression. For each scale, a total score was calculated that ranged from 0 to 28 points. The internal consistency values for the scales, measured using Cronbach's $\alpha$, were 0.90 and 0.91 , respectively.

Two additional factors were assessed using a single item each. Beliefs to be back at the same work were assessed using the question: Do you believe you will return to the same work within 6 months? These beliefs were assessed on a 10-point scale (from $1=$ highly unlikely to $10=$ highly likely). Physical activity was assessed using the question: How often do you exercise regularly for at least $30 \mathrm{~min}$, e.g., walking, jogging, swimming, cycling or working in the garden? The four response alternatives were: 0 days/week, 1-3 days/week, 4-5 days/week, 6-7 days/week.

\section{Outcome measures}

\section{Work ability}

Work ability was assessed using the Work Ability Index (WAI) [10, 37], which consists of 7 items. For each item, a single score was obtained, and the total WAI score was calculated by summing all single-item scores; the total score ranged from 7 to 49 points. Lower scores indicate lower work ability. The internal consistency of the scale, measured using Cronbach's $\alpha$, was 0.78 .

\section{Well-being}

Well-being was measured using the Life Satisfaction questionnaire (LiSat- 11) [12, 38], which consists of 11 items. Each item was rated on a 6-point ordinal scale ranging from $1=$ very dissatisfied to $6=$ very satisfied, where high scores reflect greater life satisfaction. The items were averaged to produce the index of well-being. The internal consistency of the scale, measured using Cronbach's $\alpha$, was 0.86 .

\section{Potential confounders}

Age and economic situation were considered potential confounders in the analysis. They were chosen because they were found to be important confounders in a systematic review of factors important for return-to-work among people with long-term pain in neck or back [16]. Age was measured on a continuous scale, and economic situation was assessed on a 5 -point scale (from $1=$ very dissatisfied to $5=$ very satisfied).

\section{Statistical analysis}

All data analyses were performed using the statistical software IBM SPSS, version 22. Descriptive statistics of demographic variables are presented as proportions, means and standard deviations. Scatterplots showed that all variables were normally distributed and that there were no outliers in the data. Prior to the regression 
analyses, multi-collinearity diagnostics using variance inflation factor (VIF) were applied, where all VIF values were less than 3.9, indicating no problem with multicollinearity between independent variables in the models [39]. Bivariate correlations between independent variables were also computed [40]. To determine the association between the independent variables and work ability and well-being, respectively, multiple linear regression analyses were performed separately for each of the outcomes. The analyses were performed with and without adjustment for age and economic situation, as data on 208 subjects gave sufficient statistical power to allow inclusion of all independent variables and confounders in the models simultaneously. The level of significance was set at $p<0.05$.

\section{Results}

Table 1 describes the participants' demographic characteristics. The mean age was around 50 years (range 2364 years). Ninety-six percent of the women were born in Sweden and $76 \%$ lived with a partner. Half of the women had upper secondary education, and $65 \%$ were satisfied with their economic situation. More than two-thirds of the women $(70 \%)$ had blue-collar work and 30\% whitecollar. A total of $68 \%$ of the women experienced neck/ shoulder pain, $71 \%$ back pain, and $43 \%$ had pain in both areas.

Bivariate correlation coefficients between the independent variables were smaller than 0.55 (Table 2). Table 3 presents the associations between the independent variables and work ability. The results showed that women with higher pain intensity $(\beta=-0.30, p<0.001)$ and higher job strain $(\beta=-0.12, p<0.05)$ had lower work ability, whereas women who believed more strongly that they would return to the same work within 6 months had greater work ability $(\beta=0.39, p<0.001)$. The regression model was significant $(p<0.001)$, and the independent variables explained $48 \%$ of the variance in work ability.

Table 4 shows that women with higher self-efficacy had greater well-being $(\beta=0.14, p<0.05)$. As the women's scores for depression increased, their well-being decreased by $48 \%(\beta=-0.48, p<0.001)$. Economic situation per se was significantly related to well-being $(\beta=0.14, p<0.05)$. The regression model was significant $(p<0.001)$ and explained $59 \%$ of total the variation in well-being.

\section{Discussion}

The present findings revealed that women who more strongly believed they would return to the same work had greater work ability, whereas women with higher pain intensity and higher job strain had lower work ability. Women with higher self-efficacy rated greater well-being, and women's well-being increased as their depression decreased.
Table 1 Demographic characteristics of the participants $(n=201-208)$

\begin{tabular}{|c|c|}
\hline Variables & Frequency (\%) \\
\hline Age (years) $(M, S D)$ & $49.63 \pm 9.71$ \\
\hline \multicolumn{2}{|l|}{ Country of birth } \\
\hline Sweden & $200(96)$ \\
\hline Others & $8(4)$ \\
\hline \multicolumn{2}{|l|}{ Cohabitation } \\
\hline Living with partner & $158(76)$ \\
\hline Living alone & $39(19)$ \\
\hline Living apart & $11(5)$ \\
\hline \multicolumn{2}{|l|}{ Education } \\
\hline Elementary & $42(20)$ \\
\hline Upper secondary & $104(50)$ \\
\hline University & $53(26)$ \\
\hline Others & $9(4)$ \\
\hline \multicolumn{2}{|l|}{ Types of work } \\
\hline Blue-collar & $145(70)$ \\
\hline White-collar & $63(30)$ \\
\hline aWorking life prior to SL (years) (M, SD) & $30.15 \pm 10.75$ \\
\hline \multicolumn{2}{|l|}{ Economic situation } \\
\hline Very dissatisfied & $25(12)$ \\
\hline Dissatisfied & $43(21)$ \\
\hline Acceptable & $88(42)$ \\
\hline Good & $38(18)$ \\
\hline Very good & $11(5)$ \\
\hline \multicolumn{2}{|l|}{ Pain area } \\
\hline Neck/shoulders & $142(68)$ \\
\hline Back & $148(71)$ \\
\hline Neck/shoulders and back & $89(43)$ \\
\hline Pain duration (months) (M, SD) & $83.63 \pm 99.64$ \\
\hline \multicolumn{2}{|l|}{ Physical activity } \\
\hline 0 day/week & $26(13)$ \\
\hline 1-3 days/week & $81(39)$ \\
\hline 4-5 days/week & $57(27)$ \\
\hline 6-7 days/week & $41(20)$ \\
\hline
\end{tabular}

Beliefs to be back at the same work (1-10 scale) (M, SD) $6.56 \pm 3.73$

${ }^{a}$ Total working years before being sick-listed

$M$ Mean and SD Standard deviation, SL Sick leave

\section{Work ability}

In the present study, one of the important factors for women's work ability was pain intensity. Our finding that higher pain intensity is associated with reduced work ability is not surprising and consistent with results from previous studies showing that increased MSP is independently associated with lower work ability in female laboratory technicians as well as young and old workers $[5,13]$. Other studies have found an impact of high 
Table 2 Bivariate Pearson's correlation coefficients between independent variables included in the regression analyses $(n=196-208)$

\begin{tabular}{|c|c|c|c|c|c|c|c|c|c|c|c|c|c|c|}
\hline Variables & 1 & 2 & 3 & 4 & 5 & 6 & 7 & 8 & 9 & 10 & 11 & 12 & 13 & 14 \\
\hline 1. Age & 1 & & & & & & & & & & & & & \\
\hline 2. Economic situation & 0.02 & 1 & & & & & & & & & & & & \\
\hline 3. Pain intensity & 0.14 & 0.07 & 1 & & & & & & & & & & & \\
\hline 4. Self-efficacy & 0.01 & 0.03 & $0.23^{d}$ & 1 & & & & & & & & & & \\
\hline 5. Sense of coherence & 0.09 & 0.01 & $0.32^{d}$ & -0.06 & 1 & & & & & & & & & \\
\hline 6. Divert attention & -0.06 & -0.02 & -0.12 & 0.30 & 0.41 & 1 & & & & & & & & \\
\hline 7. Ignore sensation & 0.01 & -0.10 & -0.04 & 0.01 & 0.15 & $0.23^{d}$ & 1 & & & & & & & \\
\hline 8. $\mid \mathrm{IBA}^{\mathrm{a}}$ & 0.02 & -0.10 & 0.11 & 0.04 & 0.01 & $0.43^{d}$ & $0.54^{d}$ & 1 & & & & & & \\
\hline 9. Job strain & 0.03 & -0.01 & -0.08 & 0.01 & 0.13 & -0.13 & -0.13 & 0.10 & 1 & & & & & \\
\hline 10. Support at work & -0.01 & -0.06 & -0.10 & -0.12 & 0.13 & $-0.27^{d}$ & $-0.37^{d}$ & -0.01 & -0.03 & 1 & & & & \\
\hline 11. Physical activity & -0.03 & -0.07 & 0.03 & 0.11 & -0.07 & 0.01 & 0.01 & 0.04 & -0.01 & $0.16^{c}$ & 1 & & & \\
\hline 12. $\mathrm{BBSW}^{\mathrm{b}}$ & $-0.15^{\mathrm{c}}$ & $-0.19^{d}$ & $0.23^{\mathrm{d}}$ & $-0.19^{d}$ & $-0.40^{d}$ & 0.11 & $-0.18^{a}$ & $-0.23^{d}$ & -0.06 & -0.02 & -0.07 & 1 & & \\
\hline 13. Anxiety & -0.02 & 0.04 & $-0.26^{d}$ & $0.16^{\mathrm{a}}$ & $0.25^{d}$ & $-0.47^{d}$ & $-0.55^{d}$ & 0.18 & -0.01 & 0.07 & 0.14 & $0.32^{d}$ & 1 & \\
\hline 14. Depression & -0.02 & 0.07 & -0.32 & 0.13 & $0.35^{\mathrm{d}}$ & $-0.51^{d}$ & -0.13 & -0.12 & -0.12 & -0.06 & 0.15 & $0.23^{d}$ & $0.46^{\mathrm{d}}$ & 1 \\
\hline
\end{tabular}

IBA Increase behavioral activities

${ }^{\mathrm{b}}$ BBSW Beliefs to be back at the same work

${ }^{c}$ Correlation is significant at the 0.05 level

${ }^{\mathrm{d}}$ Correlation is significant at the 0.01 level

intensity of MSP including neck/shoulder and back, on low work ability among women and men [41, 42].

We also found that high-job strain, i.e., high demands in combination with low decision latitude, was related to reduced work ability among women on long-term sick leave due to pain in the neck/shoulders and/or back. The result is in accordance with previous findings suggesting that high-job strain causes poor work ability [43]. Further, studies also found job strain to be an indicator of increased risk of long-term sick leave and MSP intensity [44, 45].

Table 3 Multiple linear regression analyses between the independent variables and work ability

\begin{tabular}{|c|c|c|c|c|c|c|}
\hline \multirow[t]{3}{*}{ Variables } & \multicolumn{6}{|c|}{ Work ability $(n=207)$} \\
\hline & \multicolumn{3}{|c|}{ Unadjusted analysis } & \multicolumn{3}{|c|}{ Adjusted analysis } \\
\hline & $\bar{\beta}$ & SE & $p$-value & $\bar{\beta}$ & SE & $p$-value \\
\hline Pain intensity & -0.32 & 0.46 & 0.001 & -0.30 & 0.47 & 0.001 \\
\hline Self-efficacy & 0.12 & 0.10 & 0.08 & 0.11 & 0.10 & 0.11 \\
\hline Sense of coherence & -0.11 & 0.05 & 0.20 & -0.10 & 0.05 & 0.31 \\
\hline Divert attention & 0.04 & 0.10 & 0.52 & 0.02 & 0.11 & 0.78 \\
\hline Ignore sensation & -0.11 & 0.09 & 0.11 & -0.12 & 0.09 & 0.10 \\
\hline Increase behavioral activities & 0.04 & 0.11 & 0.61 & 0.06 & 0.11 & 0.36 \\
\hline Job strain & -0.12 & 2.15 & 0.04 & -0.12 & 2.16 & 0.04 \\
\hline Support at work & 0.03 & 0.13 & 0.63 & 0.03 & 0.13 & 0.64 \\
\hline Physical activity & -0.03 & 0.44 & 0.62 & -0.04 & 0.45 & 0.55 \\
\hline Beliefs to be back at the same work & 0.39 & 0.12 & 0.001 & 0.39 & 0.13 & 0.001 \\
\hline Anxiety & -0.14 & 0.13 & 0.07 & -0.13 & 0.13 & 0.08 \\
\hline Depression & -0.15 & 0.15 & 0.07 & -0.15 & 0.15 & 0.06 \\
\hline Age & & & & -0.09 & 0.04 & 0.13 \\
\hline Economic situation & & & & -0.04 & 0.45 & 0.63 \\
\hline R square & 0.52 & & & 0.53 & & \\
\hline Adjusted $R^{2}$ & 0.49 & & & 0.48 & & \\
\hline
\end{tabular}


Table 4 Multiple linear regression analyses between the independent variables and well-being

\begin{tabular}{|c|c|c|c|c|c|c|}
\hline \multirow[t]{3}{*}{ Variables } & \multicolumn{6}{|c|}{ Well-being $(n=168)$} \\
\hline & \multicolumn{3}{|c|}{ Unadjusted analysis } & \multicolumn{3}{|c|}{ Adjusted analysis } \\
\hline & $\beta$ & SE & $p$-value & $\beta$ & SE & $p$-value \\
\hline Pain intensity & 0.05 & 0.55 & 0.45 & 0.06 & 0.57 & 0.36 \\
\hline Self-efficacy & 0.16 & 0.12 & 0.02 & 0.14 & 0.12 & 0.03 \\
\hline Sense of coherence & 0.17 & 0.06 & 0.04 & 0.14 & 0.06 & 0.09 \\
\hline Divert attention & -0.09 & 0.12 & 0.19 & -0.10 & 0.13 & 0.16 \\
\hline Ignore sensation & -0.04 & 0.11 & 0.52 & -0.02 & 0.11 & 0.82 \\
\hline Increase behavioral activities & 0.02 & 0.13 & 0.80 & -0.01 & 0.13 & 0.91 \\
\hline Job strain & 0.08 & 2.60 & 0.17 & 0.08 & 2.58 & 0.15 \\
\hline Support at work & -0.09 & 0.16 & 0.15 & -0.09 & 0.16 & 0.17 \\
\hline Physical activity & 0.03 & 0.53 & 0.60 & 0.03 & 0.53 & 0.65 \\
\hline Beliefs to be back at the same work & 0.02 & 0.14 & 0.78 & 0.01 & 0.15 & 0.96 \\
\hline Anxiety & -0.08 & 0.16 & 0.33 & -0.08 & 0.16 & 0.30 \\
\hline Depression & -0.49 & 0.18 & 0.001 & -0.48 & 0.18 & 0.001 \\
\hline Age & & & & -0.03 & 0.05 & 0.57 \\
\hline Economic situation & & & & 0.14 & 0.54 & 0.02 \\
\hline$R$ square & 0.62 & & & 0.63 & & \\
\hline Adjusted $R^{2}$ & 0.59 & & & 0.59 & & \\
\hline
\end{tabular}

$\beta$ Standardized regression coefficient, SE Standard Error

Note: Bold numbers represent significant values $(p<0.05)$

Our results also showed that women who believed they would return to the same work rated greater work ability. This is in line with a cross-sectional study demonstrating that internal health-related control beliefs are an important individual resource that might moderate the effect of work-related stressors on work ability [46]. A prospective cohort study also found recovery beliefs to be a predictor of return to work among male and female workers with chronic low-back pain who were receiving sickness benefits [15].

Contrary to our expectations, self-efficacy and sense of coherence did not significantly contribute to work ability. This was surprising, as they have been found to be significant in previous studies among whiplash and chronic and sub-acute MSP patients [21, 22]. Similarly, factors such as coping strategies, i.e., divert attention, ignore sensation and increase behavioral activities, and support at work did not appear to be significant in the present study, but have been found to be significant in previous studies for work ability $[19,47]$. One possible explanation is that the participants in our study were women on sick leave because support at work is likely of more importance to people who are working.

\section{Well-being}

The present study indicated that high self-efficacy was associated with increased well-being. The finding is supported by previous studies suggesting that self-efficacy is an important coping factor among chronic pain patients $[48,49]$. As expected, our study revealed an inverse association between depression and well-being, suggesting that depression decreases well-being. This was not the case for anxiety. Possibly, anxiety is obscured by the high prevalence of depression in this population [50].

In our study, different factors were identified for work ability and well-being, respectively, meaning that different factors need to be targeted to achieve greater work ability as opposed to greater well-being. For example, the factors self-efficacy and depression were found to be significant for well-being, whereas these factors were not significantly related to work ability. It should be noted, however, that the factors were close to significant for work ability. Previous studies have found self-efficacy and depression to be important for work ability in patients with chronic whiplash-associated disorder and for employees on long-term sick leave [14, 21]. Our adjusted analysis showed that the confounding factor, economic situation, itself was significantly associated with well-being. If we regard economic situation as a personal factor, it is reasonable to assume when personal economy is good, it could provide access to other coping resources that support improved well-being [51-53].

\section{Strengths and limitations}

One of the strengths of the present study is the use of validated scales to measure all independent variables and 
outcomes and use of well-defined inclusion criteria. The selection of participants was based solely on what was specified in the medical certificate issued by physician. Thus, participants' own opinions of their illness were not considered. Further, pain figure was used in order to check with the information about pain in the neck/shoulders and/or back. In the invitation letter sent to the participants, it was stressed that the project was made in collaboration between the SIA and the University of Gävle, and that non-response would not affect the women's right to compensation. We believe that our results were not affected by SIA selecting participants. Two of the authors (MLK, AN) instructed personnel at SIA in how to select participants based on the inclusion and exclusion criteria.

The study has some limitations that should be noted. The number of non-response could raise questions about potential selection bias. We believe there are two major reasons for the low response rate: (i) participation was voluntary and no compensation was offered, and (ii) participants were unable to answer all the questions due to pain. To increase the response rate, we sent two consecutive reminders. As the study was cross-sectional in design, inferences about cause and effect cannot be made. Longitudinal studies are required to confirm these results. Job strain and support at work, as measured by the DCSQ, showed low internal consistency. Because work ability and well-being were measured using self-reported data, it is possible that the results would have been different if objective measurements had been applied.

\section{Conclusion}

The present findings suggest that beliefs to be back at the same work, pain intensity and job strain are predictors of work ability, while self-efficacy and depression are predictive of well-being among women on sick leave due to long-term pain in neck/shoulders and/or back. Hence, the present study showed that the factors associated with work ability were not the same as those associated with well-being in this population. Given the differences between the outcomes, we believe it is important to consider work ability as well as well-being in the population. The findings highlight factors that should be considered by health care professionals and policy-makers to guide attempts to reduce sick leave. The results may not be generalizable to men, as gender may modify the examined relations.

\section{Abbreviations}

CSQ: Coping Strategies Questionnaire; DCSQ: Demand Control Support Questionnaire; GSE: General Self-Efficacy; HADS: Hospital Anxiety and Depression Scale; LiSat: Life Satisfaction; MPI: Multidimensional Pain Inventory; MSP: Musculoskeletal pain; SOC: Sense of Coherence; VIF: Variance Inflation Factor; WAI: Work Ability Index

\section{Acknowledgements}

The authors would like to extend their gratitude to all of the study participants as well as to the Swedish Social Insurance Agency who assisted us in the data collection.

\section{Funding}

This project was supported by University of Gävle (Reg. no. 2015/424).

\section{Availability of data and materials}

The dataset underlying the present findings is available from the corresponding author upon reasonable request.

\section{Authors' contributions}

MR co-developed the study design, performed data collection, processing and analyses and drafted the manuscript. M-L K co-developed the study design, performed data collection, and reviewed the initial drafts of the manuscript. $\mathrm{MH}$ co-developed the study design, contributed to the analyses, and reviewed the initial drafts of the manuscript. AN co-developed the study design, performed data collection, processing and analyses, and reviewed the initial drafts of the manuscript. All authors have read and approved the final manuscript.

\section{Ethics approval and consent to participate}

This project was approved by the Regional Ethical Review Board, Uppsala, Sweden (Reg. no. 2.3.2-2015/548). A letter accompanying the questionnaire provided information about the study content and assured the confidentiality of the information. All participants provided their signed informed consent at the time of data collection.

\section{Competing interests}

The authors declare that they have no competing interests.

\section{Publisher's Note}

Springer Nature remains neutral with regard to jurisdictional claims in published maps and institutional affiliations.

\section{Author details}

${ }^{1}$ Centre for Musculoskeletal Research, Department of Occupational and Public Health Sciences, Faculty of Health and Occupational Studies, University of Gävle, SE-80176 Gävle, Sweden. ${ }^{2}$ Department of Health and Caring Sciences, Faculty of Health and Occupational Studies, University of Gävle, Gävle, Sweden. ${ }^{3}$ Department of Public Health and Caring Sciences, Faculty of Medicine, Uppsala University, Uppsala, Sweden.

Received: 10 November 2017 Accepted: 21 May 2018

Published online: 30 May 2018

\section{References}

1. Alexanderson $\mathrm{K}$, Norlund A. Swedish council on technology assessment in health care (SBU). Chapter 1. Aim, background, key concepts, regulations, and current statistics. Scandinavian journal of public health. Supplement. England. 2004;63:12-30.

2. Hubertsson J, Englund M, Hallgårde U, Lidwall U, Löfvendahl S, Petersson IF. Sick leave patterns in common musculoskeletal disorders - a study of doctor prescribed sick leave. BMC Musculoskelet Disord. 2014;15:176.

3. Sell L. Predicting long-term sickness absence and early retirement pension from self-reported work ability. Int Arch Occup Environ Health. 2009:82:1133-8.

4. Lingren L, Gomez-Barrena E, Duda GN, Puhl W, Carr A. European musculoskeletal health and mobility in horizon 2020: SETTING PRIORITIES FOR MUSCULOSKELETAL RESEARCH AND. Bone Joint Res. 2014;3(3):48-50.

5. Bugajska J, Sagan A. Chronic musculoskeletal disorders as risk factors for reduced work ability in younger and ageing workers. Int J Occup Saf Ergon. 2014;20:607-15.

6. Wijnhoven HAH, de Vet HCW, Picavet HSJ. Prevalence of musculoskeletal disorders is systematically higher in women than in men. The clinical journal of pain. United States. 2006;22:717-24.

7. Thorsen SV, Friborg C, Lundstrøm B, Kausto J, Örnelius K, Sundell T, et al. Sickness Absence in the Nordic Countries [Internet]. 2015. Available from: http://norden.diva-portal.org/smash/get/diva2:811504/FULLTEXT06.pdf

8. IImarinen J. Work ability - a comprehensive concept for occupational health research and prevention. Scand j work Environ Health. 2009;35:1-5. 
9. Ludvigsson $M$, Svensson T. Begreppet arbetsförmåga - en litteraturgenomgång [The concept work ability - a literature review]. Stockcholm: Arbete och Hälsa; 2006.

10. Tuomi K, Ilmarinen J, Jahkola A, Katajarinne L, Tulkki A. Work ability index. Helsinki: Finnish institute of Occupational Health; 1998.

11. Diener E. Assessing well-being: the collected works of Ed Diener. In: Assessing well-being: the collected works of Ed Diener. New York, NY: springer science + business Media; 2009.

12. Fugl-Meyer AR, Melin R, Fugl-Meyer KS. Life satisfaction in 18- to 64-year-old swedes: in relation to gender, age, partner and immigrant status. J Rehabil Med. 2002;34:239-46.

13. Jay K, Friborg MK, Sjogaard G, Jakobsen MD, Sundstrup E, Brandt M, et al. The consequence of combined pain and stress on work ability in female laboratory technicians: a cross-sectional study. Int J Environ Res Public Health. 2015;12:15834-42.

14. Lindberg P, Vingård E, Josephson M, Alfredsson L. Retaining the ability to work - associated factors at work. Eur J Pub Health. 2006;16:470-5.

15. Gross DP, Battie MC. Work-related recovery expectations and the prognosis of chronic low back pain within a workers' compensation setting. J Occup Environ Med. 2005;47:428-33.

16. Rashid M, Kristofferzon M, Nilsson A, Heiden M. Factors associated with return to work among people on work absence due to long-term neck or back pain : a narrative systematic review. BMJ Open. 2017;7:1-10.

17. van den Berg TIJ, Elders $L$ a $M$, de Zwart $B C H$, Burdorf a. The effects of work-related and individual factors on the work ability index: a systematic review. Occup Environ Med. 2009;66:211-20.

18. Hoogendoorn WE, van Poppel MN, Bongers PM, Koes BW, Bouter LM. Systematic review of psychosocial factors at work and private life as risk factors for back pain. Spine United States. 2000;25:2114-25.

19. Dekkers-Sánchez PM, Wind H, Sluiter JK, Frings-Dresen MHW. What factors are most relevant to the assessment of work ability of employees on longterm sick leave? The physicians' perspective. Int Arch Occup Environ Health. 2013:509-18.

20. Sjögren-Rönkä T, Ojanen MT, Leskinen EK, Mustalampi STME. Physical and psychosocial prerequisites of functioning in relation to work ability and general subjective well-being among office workers. Scand I Work Environ Health. 2002;28:184-90.

21. Agnew $L$, Johnston $V$, Ludvigsson $M L$, Peterson $G$, Overmeer $T$, Johansson $G$, et al. Factors associated with work ability in patients with chronic whiplash-associated disorder grade II-III: a cross-sectional analysis. J Rehabil Med. 2015:47:546-51.

22. Denison E, Åsenlöf P, Lindberg P. Self-efficacy, Fear avoidance, and pain intensity as predictors of disability in subacute and chronic musculoskeletal pain patients in primary health care. Pain. 2004;111:245-52.

23. Chumbler NR, Kroenke K, Outcalt S, Bair MJ, Krebs E, Wu J, et al. Association between sense of coherence and health-related quality of life among primary care patients with chronic musculoskeletal pain. Health Qual Life Outcomes. 2013;11:216.

24. Hansson E, Hansson T, Jonsson R. Predictors for work ability and disability in men and women with low-back or neck problems. Eur Spine J. 2006;15:780-93.

25. Laaksonen M, Mastekaasa A, Martikainen P, Rahkonen O, Piha K, Lahelma E. Gender differences in sickness absence - the contribution of occupation and workplace. Scand J Work Environ Health. 2010;36:394-403.

26. Lewis C, Mathiassen SE. State of knowledge report: physical work, gender, and health in working life [internet]. 2013. Available from: https:/www.av. se/globalassets/filer/publikationer/kunskapssammanstallningar/physicalwork-gender-and-health-in-working-life-kunskapssammanstallning-2013-9eng.pdf

27. Margolis RB, Tait RC, Krause SJ. A rating system for use with patient pain drawings. Pain United States. 1986;24:57-65.

28. Bergström G, Jensen IB, Bodin L, Linton SJ, Nygren ÅL, Carlsson SG. Reliability and Factor structure of the multidimensional pain inventory Swedish language version (MPI-S). Pain. 1998;75:101-10.

29. Luszczynska A, Scholz U, Schwarzer R. The general self-efficacy Scale : multicultural validation studies. The Journal of Psychology. 2005;139:439-547.

30. Antonovsky A. The structure and properties of the sense of coherence scale. Social science \& medicine (1982). England. 1993;36:725-33.

31. Eriksson M, Lindstro B. Validity of Antonovsky's sense of coherence scale: a systematic review. J Epidemiol Community Health. 2005;59:460-6.

32. Jensen IB, Linton SJ. Coping strategies questionnaire (CSQ): reliability of the Swedish version of the CSQ. Scand J Behav Ther. 1993;22:139-45.
33. Chungkham HS, Ingre M, Karasek R, Westerlund H, Theorell T. Factor structure and longitudinal measurement invariance of the demand control support model: an evidence from the Swedish longitudinal occupational survey of health (SLOSH). PLoS One. 2013;8

34. Sanne B, Torp S, Mykletun A, A a D. The Swedish demand-control-support questionnaire (DCSQ): factor structure, item analyses, and internal consistency in a large population. Scandinavian Journal of Public Health. 2005;33:166-74.

35. Zigmond AS, Snaith RP. The hospital anxiety and depression scale. Acta Psychiatrica Scandinavica Wiley Online Library. 1983;67:361-70.

36. Annunziata MA, Muzzatti B, Altoé G. Defining hospital anxiety and depression scale (HADS) structure by confirmatory factor analysis: a contribution to validation for oncological settings. Ann Oncol. 2011;22:2330-3.

37. Bethge $M$, Radoschewski FM, Gutenbrunner $C$. The work ability index as a screening tool to identify the need for rehabilitation: longitudinal findings from the second German Sociomedical panel of employees. J Rehabil Med. 2012;44:980-7.

38. Maujean A, Devis P. The relationship between self-efficacy and well-being in stroke survivors. International Journal of Physical Medicine \& Rehabilitation. 2013:4:1-10.

39. O'Brien RM. A caution regarding rules of thumb for variance inflation factors. Qual Quant. 2007;41:673-90.

40. Yoo W, Mayberry R, Bae S, Singh K, He Q, Lillard J Jr. A study of effects of multicollinearity in the multivariable analysis. International Journal of Applied Science and Technology. 2014;4:9.

41. Lindegård A, Larsman P, Hadzibajramovic E, Ahlborg G, Oberlinner C, Yong $M$, et al. Combined effect of back pain and stress on work ability. Occ med. 2015;87:147-53.

42. Lindegård A, Larsman P, Hadzibajramovic E, Ahlborg G. The influence of perceived stress and musculoskeletal pain on work performance and work ability in Swedish health care workers. Int Arch Occup Environ Health. 2014;87:373-9.

43. Li H, Liu Z, Liu R, Li L, Lin A. The relationship between work stress and work ability among power supply workers in Guangdong, China: a cross-sectional study. BMC Public Health. 2016;16:123.

44. Lidwall U, Marklund S. What is healthy work for women and men ? - a case-control study of gender- and sector-specific effects of psycho-social working conditions on long-term sickness absence. Work. 2006;27:153-63.

45. Ahlberg-Hulten GK, Theorell T, Sigala F. Social support, job strain and musculoskeletal pain among female health care personnel. Scand J Work Environ Health. 1995;21:435-9.

46. Bethge M, Radoschewski FM. Physical and psychosocial work stressors, health-related control beliefs and work ability: cross-sectional findings from the German sociomedical panel of employees. Int Arch Occup Environ Health. 2010:83:241-50.

47. Alavinia SM, de Boer AGEM, van Duivenbooden JC, Frings-Dresen MHW, Burdorf A. Determinants of work ability and its predictive value for disability. Occup Med. 2009:59:32-7.

48. Nilsson A, Sjödén PO, Dahl J, Denison E. Factors related to long-duration pain and sick leave among Swedish staff working in the public health service. Scand J Caring Sci. 2005:19:419-26.

49. Chang A-K, Park J, Sok SR. Relationships among self-efficacy, depression, life satisfaction, and adaptation among older Korean adults residing in for-profit professional nursing facilities. The journal of nursing research : JNR China (Republic : 1949- ). 2013;21:162-9.

50. Albert PR. Why is depression more prevalent in women? I Psychiatry Neurosci. 2015;40:219-21.

51. Campbell A. Subjective measures of well-being. In: American Psychologist. US: American Psychological Association; 1976. p. 117-24.

52. Ferrer-i-Carbonell A. Income and well-being: an empirical analysis of the comparison income effect. J Public Econ. 2005;89:997-1019.

53. Krohne HW. Stress and coping theories. Stress The International Journal on the Biology of Stress. 2002;22:15163-70. 